\title{
Conditioned Opioid Withdrawal Decreases Nociceptin/Orphanin FQ Levels in the Frontal Cortex and Olfactory Tubercle
}

\author{
John R. Walker, Ph.D., Lars Terenius, Ph.D., and George F. Koob, Ph.D.
}

Clinical evidence suggests that individuals experiencing drug withdrawal can become conditioned to environmental situations, whereby previously neutral stimuli can produce symptoms of withdrawal. It is believed that this "conditioned withdrawal" can have motivational significance, but the neurobiological basis for conditioned withdrawal is unknown. The goal of this study was to determine adaptations in endogenous opioid systems that may be responsible for expression of conditioned withdrawal. Opioid-dependent rats trained to lever press for food were exposed to tone and scent cues in the presence of naloxone or saline. Naloxone but not saline predictably suppressed responding for food. One month later and in a post-dependent state, all rats again were exposed to the cues but not naloxone. The conditioned cues alone suppressed responding for food in the rats previously paired with naloxone, but no suppression was seen in rats previously paired with saline. Radioimmunoassay (RIA) analysis for nociceptin/orphanin FQ (nociceptin), met-enkephalin-ArgPhe (MEAP), and dynorphin A (dyn A) was performed from dissections of various brain regions of the rats undergoing conditioned withdrawal. Significant reductions in nociceptin peptide levels were seen in the frontal cortex and olfactory tubercle of these rats. Unconditioned opioid withdrawal and unconditioned footshock stress produced different patterns of opioid peptide regulation in separate groups of rats. These results shed light on adaptations of endogenous opioid systems to conditioned cues, stress, and withdrawal, all factors that play a role in motivating drug intake.

[Neuropsychopharmacology 27:203-211, 2002]

(C) 2002 American College of Neuropsychopharmacology.

Published by Elsevier Science Inc.
KEY WORDS: Opioid peptide; Withdrawal; Conditioning; Stress; Frontal cortex; Olfactory tubercle

From the Department of Neuropharmacology, The Scripps Research Institute, La Jolla, CA, USA (JRW, GFK), and the Department of Clinical Neuroscience, Experimental Alcohol and Drug Addiction Research Section, Karolinska Hospital, Stockholm, Sweden (LT).

Address correspondence to: John R. Walker, Genomics Institute of the Novartis Research Foundation, 10675 John Jay Hopkins Dr., Room 129, San Diego, CA 92121. Tel.: (858) 812-1636; Fax: (858) 8121746; E-mail: walker@gnf.org

Received August 30, 2001; revised January 9, 2002; accepted January 16, 2002.

Online publication: $1 / 21 / 02$ at www.acnp.org/citations/ Npp012102228.
Abrupt termination of chronic opioid intake leads to myriad somatic and affective symptoms defined as the opioid withdrawal syndrome (O'Brien 1996). Some components of the opioid withdrawal syndrome are susceptible to classical conditioning and may surface on reexposure to certain cues associated with drug withdrawal. Experience with human patients and experiments in monkeys have demonstrated that reexposure to cues that have been paired with opioid withdrawal lead to drug seeking that may be linked to alleviation of conditioned withdrawal (Goldberg et al. 1969; Wikler 1973; O'Brien et al. 1977). One reason drug treatment programs have a high failure rate may be caused by their inability to extinguish these conditioned environ- 
mental stimuli. Understanding how conditioned cues contribute to relapse is a major focus of drug addiction research (O'Brien et al. 1998).

The neuroanatomical and neurochemical systems involved in integrating conditioned cues with withdrawal-like physiologic responses are not well understood. Brain regions that may play a role in conditioned opioid withdrawal include various amygdaloid nuclei, the nucleus accumbens (Acb), and the bed nucleus of the stria terminalis (Schulteis et al. 2000). These regions have a rich density of opioid peptides and receptors, suggesting a role for the opioid system in modulating conditioned opioid withdrawal (Mansour et al. 1995). Disruption in endogenous opioid function during withdrawal may be hypothesized to contribute to withdrawal discomfort and may motivate drug seeking. Similar changes may occur during conditioned withdrawal. The purpose of this study was to begin testing this hypothesis by examining opioid peptide levels during conditioned opioid withdrawal in specific brain regions involved in drug addiction. The peptides chosen for analysis were all endogenous opioids with different opioid receptor-binding properties, yet they have all been implicated in the reinforcing properties of abused drugs (Reisine and Pasternak 1996; Cappendijk et al. 1999; Lindholm et al. 2000; Ciccocioppo et al. 2000).

\section{MATERIALS AND METHODS}

\section{Animals}

Subjects were 57 male Wistar rats (Charles River, Kingston, NY) weighing 350-500 g at the start of experimental testing. Twenty-four rats were used for the conditioned withdrawal experiment, 15 rats were used for the unconditioned withdrawal experiment, and 18 rats were used for the unconditioned stress experiment. Rats were housed in groups of three per cage, in a room with a 12-h light/12-h dark cycle (lights off 6 PM), until they reached weights of approximately $300 \mathrm{~g}$. Rats then were housed in groups of two per cage. Water was freely available when rats were in their home cages. All experimental testing sessions were less than 1 hour per day, and occurred during the rats' active phase (lights off). All experiments were performed in accordance with the National Institutes of Health Guide for the Care and Use of Laboratory Animals.

\section{Drugs}

Naloxone hydrochloride was purchased from Sigma (St. Louis, MO). Morphine sulfate and morphine sulfate pellets were from the National Institute on Drug Abuse (NIDA). Drugs were injected subcutaneously in a volume of $1 \mathrm{ml}$ per kilogram body weight using saline as the vehicle.

\section{Conditioned Withdrawal Induction}

The method to produce conditioned opioid withdrawal was from a previous study from this laboratory with minor modifications (Baldwin and Koob 1993). Briefly, rats were trained to respond for food in an operant chamber while they were food-restricted $(10 \mathrm{~g}$ food per day in the home cage). Responding for $45 \mathrm{mg}$ food pellets (P.J. Noyes, Lancaster, NH) was started on a fixed ratio 1 (FR1) time out 1-s schedule. As rats learned the operant procedure, the response requirement was gradually increased to FR15. All rats then were implanted with two $75 \mathrm{mg}$ subcutaneous morphine pellets to begin the conditioning phase of the experiment. All operant sessions began with 10 minutes of responding for food. This pre-injection baseline period was to examine if conditioning occurs to the context alone, and to track any irregular baseline responding produced by morphine pellet implantation, an effect observed in our laboratory. Rats were removed after the 10-minute session, given a subcutaneous saline injection, and returned to the operant chamber for an additional 20-minute session. On days 7 and 8 post-morphine pellets, rats were separated into two groups. One group received saline (unpaired group) and the other group received naloxone $(0.025 \mathrm{mg} / \mathrm{kg}$, s.c.; paired group) 10 minutes into a 30-minute session. Immediately after the injections, a scent cue (anise extract) and a sound cue $(7-\mathrm{kHz}, 85 \mathrm{~dB})$ were delivered to all rats in the operant chambers for 20-minute sessions. On day 9 rats were given a baseline response day without cues, and on days 10 and 11 conditioning sessions were resumed. Rats in the paired group received saline injections in their home cages 3 hours after the conditioning sessions, and unpaired rats received $0.025-\mathrm{mg} / \mathrm{kg}$ naloxone. Rats were never exposed to the tone/scent combination outside of the context of a conditioning session.

After conditioning sessions were completed, morphine pellets were removed, and the 10-minute followed by 20-minute sessions, minus cues, were continued for 1 month. For the final session, all rats were exposed to the tone/scent combination after a saline injection and operant responding was recorded for 20 minutes. Rats were immediately returned to their home cages and were sacrificed by decapitation 2 hours later.

\section{Unconditioned Withdrawal Induction}

To determine if the peptide level changes measured with conditioned withdrawal were caused by manifestation of symptoms associated with unconditioned opioid withdrawal, rats were sacrificed after exposure to mild unconditioned opioid withdrawal (Schulteis et al. 1997). Several conditions had to be modified to ensure that the quality of withdrawal in our unconditioned withdrawal experiment most accurately modeled con- 
ditioned withdrawal. First, rats in the conditioned withdrawal experiment were sacrificed 1 month after the last morphine exposure, and thus no longer in a dependent state. It is not possible to induce unconditioned opioid withdrawal in a nondependent state. Second, the degree of unconditioned withdrawal with morphine pellets implanted can be more severe than conditioned withdrawal. For example, it was evident from our data that the degree of suppression of operant responding for food was much greater during the conditioning sessions (with morphine pellets implanted) than when the rats were tested in the post-dependent state. Thus, a situation was desired in which rats were dependent enough to induce a mild withdrawal state with rarely detectable physical signs when naloxone was administered, yet not in a state where a high degree of dependence would induce severe withdrawal and possibly exaggerate changes in peptide levels.

Fifteen rats were habituated to subcutaneous saline injections for 3 days. On day 4, all rats were given a subcutaneous injection of morphine $(5 \mathrm{mg} / \mathrm{kg})$. On day 5 , all rats were again given morphine $(5 \mathrm{mg} / \mathrm{kg}$ ). Four hours later, half of the rats were given saline and the other half were given naloxone $(0.3 \mathrm{mg} / \mathrm{kg}$, s.c.). This combination of morphine and naloxone previously had been shown to produce an equivalent suppression of operant responding for food as observed in the present studies (Schulteis et al. 1997). Two hours after this treatment, all rats were sacrificed by decapitation.

\section{Unconditioned Stress Induction}

To rule out the possibility that the peptide level changes observed with conditioned withdrawal were caused by stress associated with withdrawal, a group of rats was exposed to mild footshock stress and brain peptide levels were examined. Conditions of exposure to stress were intended to mimic as closely as possible the conditions the previous rats experienced during conditioned withdrawal (i.e., repeated stimuli) yet ensure that the footshock stress during the final session was unpredictable and therefore unconditioned.

Eighteen rats were habituated to operant chambers for 15 minutes for 2 days. Operant chambers were equipped with a floor that allowed for the delivery of $0.4 \mathrm{~mA}$ of current for 0.5 seconds duration at varied intervals every $10-50$ seconds. A similar method of footshock stress has been used to induce relapse to drug seeking (Shaham and Stewart 1996). Rats were divided into two groups: One group received footshock stress on the indicated days, and the other group never received footshock stress but was placed only in the operant chambers. On days 3 and 4, shock was delivered during the last 10 minutes of a 15-minute session. On day 5 , rats were habituated to the chamber without delivery of a shock. On days 6 and 7, rats were again ex- posed to footshock. For the following 1 month and for 5 days per week, rats were exposed to the operant chambers without footshock to extinguish any possible association between exposure to operant chambers and footshock stress. On the last day of exposure to the operant chambers, rats were again exposed to footshock stress, returned to their home cages, and sacrificed by decapitation 2 hours later. Unshocked rats were placed in the operant chamber without footshock stress and were sacrificed 2 hours later.

\section{Analysis of Peptide Levels}

After decapitation, rat brains were immediately dissected on ice, and brain regions were immediately transferred to dry ice for storage. Tissue extraction was performed with $1 \mathrm{M}$ acetic acid. The samples were heated at $95^{\circ} \mathrm{C}$ for 5 minutes, and after cooling on ice the tissues were homogenized by sonication using a Branson Sonifier. The samples were reheated at $95^{\circ} \mathrm{C}$ for 5 minutes, cooled on ice, and then centrifuged for 15 minutes at $12,000 \mathrm{~g}$ in a Beckman Microfuge. The supernatants were applied onto small $(1 \mathrm{ml})$ ion exchange columns containing SP Sephadex C-25 gel to concentrate and separate opioid peptides in the tissue extract. Peptides were eluted with buffers containing mixtures of pyridine $(\mathrm{P})$ and formic acid (F): I = 0.018 M P: 0.1 M F, II = 0.1 M Pyr: 0.1 M F (elutes Met-enkephalin-Arg-Pre or MEAP), and III $=0.35$ M P: 0.35 M F, IV = 1.6 M Pyr: 1.6 M F (elutes dynorphin $\mathrm{A}$, nociceptin). The fractions were dried in a vacuum centrifuge and stored at $-20^{\circ} \mathrm{C}$ until peptide analysis. The following procedures have been described in detail elsewhere (Bergström et al. 1983; Christensson-Nylander et al. 1985).

Specific radioimmunoassays were performed for dynorphin A, MEAP, and nociceptin, respectively. The respective antiserum was diluted with gelatin buffer. The peptides were labeled with ${ }^{125} \mathrm{I}$ using chloramine-T and purified with reversed phase HPLC using a gradient of $15 \%-40 \%$ acetonitrile, in $0.04 \%$ trifluoroacetic acid. The tracer with peptide was diluted with gelatin buffer to $4500 \mathrm{cpm} / 100 \mu \mathrm{l}$. The samples or standard peptide ( $25 \mu \mathrm{l})$ were incubated with $100 \mu \mathrm{l}$ antiserum and $100 \mu \mathrm{l}$ of labeled peptide for $24 \mathrm{~h}$. In dynorphin A and nociceptin assays, the gelatin buffer contained $0.15 \mathrm{M} \mathrm{NaCl}, 0.02 \%$ sodium azide, $0.1 \%$ gelatin, $0.1 \%$ Triton $\mathrm{X}-100$, and $0.1 \%$ bovine serum albumin in $0.05 \mathrm{M}$ sodium phosphate buffer $\mathrm{pH}$ 7. Free and antibody-bound peptide were separated by incubation for $1 \mathrm{~h}$ with $100 \mu \mathrm{l}$ sheep antirabbit antiserum (Pharmacia, North Peapack, NJ). After centrifugation, the radioactivity in the pellets was counted in a $\gamma$ counter. Dynorphin A antiserum (84+) was used in a final dilution of 1:500,000 and nociceptin antiserum (96:2C) was diluted 1:60,000.

In MEAP assays, a gelatin buffer was used containing $0.15 \mathrm{M} \mathrm{NaCl}, 0.025 \mathrm{M}$ EDTA, $0.1 \%$ gelatin, and $0.1 \%$ 
bovine serum albumin in $0.05 \mathrm{M}$ sodium phosphate buffer, $\mathrm{pH}$ 7. A charcoal suspension $(250 \mathrm{mg}$ and $25 \mathrm{mg}$ dextran T-70 in $100 \mathrm{ml} 0.05 \mathrm{M}$ sodium phosphate buffer) was added to the samples ( $200 \mu \mathrm{l} /$ sample), which were incubated for 10 minutes and thereafter centrifuged for 1 minute. The supernatant $(300 \mu \mathrm{l})$ was counted in a $\gamma$ counter. MEAP antiserum (90:3D II) was used at a final dilution of 1:140,000.

\section{Statistical Analyses}

Baseline lever pressing rates were defined as the average number of lever presses during the last $20 \mathrm{~min}$ of three 30-minute sessions after morphine pellet implantation yet prior to beginning conditioning or testing. Differences in baseline response rates were compared by a two-tailed Student's $t$-test. During the conditioning phase of the experiment, results were analyzed by twoway ANOVA with group (unpaired vs. paired) as the between-subjects factor and with repeated measures on day of conditioning procedure. The 10-minute pre-injection period during the conditioning phase was examined by two-way ANOVA with group (unpaired vs. paired) as the between-subjects factor and with repeated measures on day of conditioning procedure. These baseline sessions were also examined within the paired group by one-way ANOVA. During the test for conditioned withdrawal, results were analyzed by twoway ANOVA with group (paired vs. unpaired) as the between-subjects factor and with repeated measures on the time since the start of the conditioned stimulus. Post hoc comparisons were carried out using tests for simple main effects. Brain peptide levels were expressed as femtomoles per milligram protein and were compared by a two-tailed unpaired Student's $t$-test.

\section{RESULTS}

For the conditioned withdrawal phase of the experiment, rats lever-pressed on a FR-15 schedule for food reinforcement. Prior to conditioning and while the mor- phine pellets were implanted, the rats that were to be put into the paired group (naloxone paired with tone and scent) pressed the lever significantly more times than the rats that were to be put into the unpaired group (saline paired with tone and scent), though groups were treated equivalently at this stage. When the last 20 minutes of the final three baseline sessions before conditioning were compared, unpaired rats pressed the lever $1026 \pm 95$ times while the paired rats pressed the lever $1492 \pm 124$ times ( $p<.01$ by Student's $t$-test).

During the conditioning phase of the experiment, saline (unpaired group) or naloxone (paired group) was given immediately prior to exposure to a tone and scent combination. When the 10-minute baseline sessions before injections were compared, two-way ANOVA revealed no significant differences between the paired and unpaired groups on conditioning days $(\mathrm{F}[1,22]=$ $0.817, p=.376$, NS). One-way ANOVA analysis of the paired group revealed a significant increase in the 10-minute pre-injection baseline response rate on conditioning days $1-4(\mathrm{~F}[3,44]=3.52, p<.05)$ (Table 1$)$. Two-way ANOVA analysis indicated that naloxone injections suppressed lever-pressing behavior (paired group) while saline did not (unpaired group) $(\mathrm{F}[1,22]=90.4, p<$ $.001)$. Specifically, paired responding was $7.2,3.2,0.6$, and $0.1 \%$ of their pre-conditioning baseline on days $1,2,3$, and 4 of conditioning, respectively (Figure 1). Similar results were produced when the number of responses rather than the percentage baseline responding was expressed, i.e., the elevated baseline in the paired group had no effect on the degree of suppression of responding (data not shown). Naloxone injections also produced diarrhea in some rats, but not vocalization and weight loss as previously reported (Baldwin and Koob 1993). Physical signs were not systematically quantified at any time in this study.

One month after conditioning and when the rats were in a post-dependent state, exposure to the tonescent combination significantly suppressed responding in the paired group, but not the unpaired group (Figure 2). Two-way ANOVA revealed a significant difference between the groups (paired vs. unpaired) across the 20-minute test session and a group-time interaction

Table 1. Pretreatment Baseline (First 10 Minutes) Response Rates Before and During Conditioning

\begin{tabular}{|c|c|c|c|c|c|c|c|c|}
\hline \multirow[b]{3}{*}{ Group } & \multicolumn{8}{|c|}{ Days Post-morphine pellet Implantation } \\
\hline & \multicolumn{3}{|c|}{ Preconditioning } & \multicolumn{2}{|c|}{ Conditioning } & \multirow{2}{*}{$\frac{\text { NC }}{\text { Day } 9}$} & \multicolumn{2}{|c|}{ Conditioning } \\
\hline & Day 4 & Day 5 & Day 6 & Day 7 & Day 8 & & Day 10 & Day 11 \\
\hline Unpaired & $582 \pm 97$ & $679 \pm 111$ & $661 \pm 91$ & $740 \pm 93$ & $901 \pm 125$ & $840 \pm 81$ & $858 \pm 99$ & $981 \pm 87$ \\
\hline Paired & $960 \pm 81$ & $863 \pm 111$ & $768 \pm 116$ & $777 \pm 95$ & $927 \pm 105$ & $987 \pm 102$ & $1083 \pm 76^{*}$ & $1126 \pm 75^{* *}$ \\
\hline
\end{tabular}

NC refers to a baseline session with no conditioning.

ANOVA analysis of conditioning sessions (Days 7, 8, 10 and 11) revealed an increase in responding in the paired group.

** $\mathrm{P}<0.01, * \mathrm{P}<0.05$, compared with Day 7 (Day 1 of conditioning). 


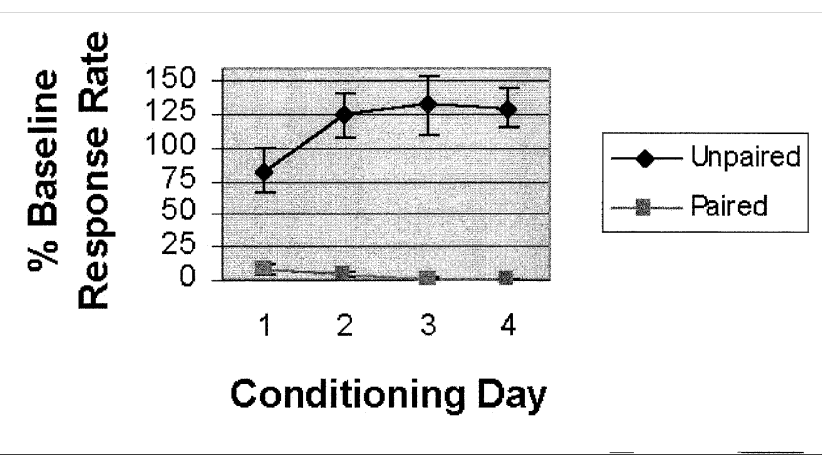

Figure 1. Effect of conditioning procedure on operant responding in opioid-dependent rats. Morphine-dependent rats that received naloxone injections $(0.025 \mathrm{mg} / \mathrm{kg}$, s.c. $)$ (paired) suppressed operant responding for food compared with rats that received saline injections (unpaired). Results are expressed as the percentage baseline responding, defined as the average rate of responding over the 3 sessions prior to conditioning while morphine pellets were implanted. The last $20 \mathrm{~min}$ of baseline sessions (after saline injections) were compared with the last $20 \mathrm{~min}$ of conditioning sessions (after naloxone or saline). Two-way ANOVA revealed significant differences between the paired and unpaired groups during conditioning $(\mathrm{F}[1,22]=90.4, p<.001)$.

$(\mathrm{F}[3,63]=7.05, p<.001)$. Post hoc analysis revealed significant differences between the groups during the first 10 minutes of the session, after which responding in the paired group began to approach pre-test baseline values. Some diarrhea was observed in the paired rats, but this was not systematically quantified. No other physical withdrawal signs were observed.

Nociceptin, MEAP), and dynorphin A peptide levels in the olfactory tubercle, frontal cortex, Acb, anterior striatum, posterior striatum, and amygdala were examined in paired versus unpaired rats 2 hours after the final testing session. Nociceptin levels were significantly suppressed in the frontal cortex $(p<.05$, Student's $t$-test) and olfactory tubercle $(p<.01)$ of paired versus unpaired rats (Figure 3). There were no significant dynorphin A or MEAP level differences between the groups (data not shown).

In order to determine whether the changes in opioid peptide levels were specific to conditioned opioid withdrawal, peptide levels were examined after mild unconditioned opioid withdrawal. Two-days exposure to morphine, followed by a naloxone injection 4 hours later, previously has been shown to suppress operant responding for food (Schulteis et al. 1997). A naloxone dose was chosen which in the previous study suppressed operant responding to a similar degree observed in Figure 2. Diarrhea was the only physical withdrawal sign seen after naloxone injection. It was observed in only a few rats, and this effect was not quantified. Nociceptin peptide levels were significantly decreased in the Acb

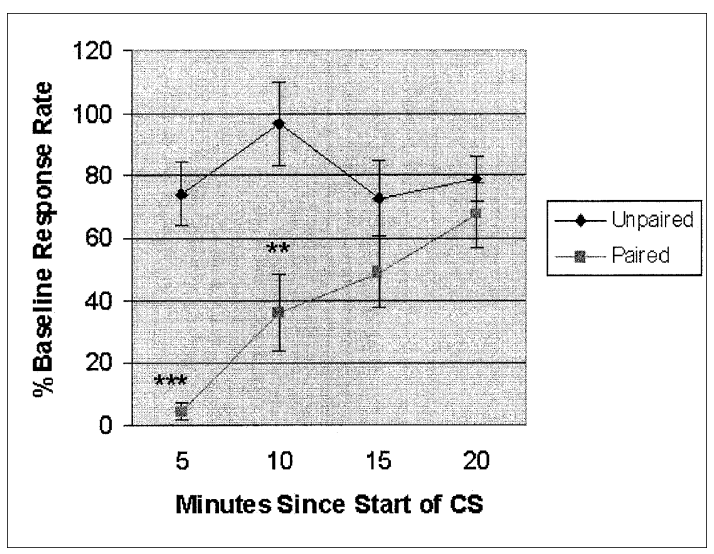

Figure 2. Test of conditioned withdrawal in post-dependent rats. One month after conditioning and in a post-dependent state, rats were reexposed to the tone-scent combination, which was previously paired with opioid withdrawal (paired) or saline (unpaired). Results are expressed as the percentage baseline responding, defined as the average rate of responding over the 3 sessions prior to the test. Paired rats significantly suppressed operant responding compared with unpaired rats. Two-way analysis of variance revealed significant effects of group (paired vs. unpaired) and time since exposure to the conditioned stimulus, and a significant interaction between the two factors $(\mathrm{F}[3,63]=7.05, p<.001)$. Post hoc analyses revealed significant differences between the two groups $5 \mathrm{~min}$ and $10 \mathrm{~min}$ after exposure to the conditioned stimulus. ${ }^{* *} p<.01,{ }^{* * *} p<.001$ differences between paired and unpaired.

$(p<.05)$ and increased in the frontal cortex $(p<.01) 2$ hours after naloxone challenge compared with salinechallenged rats (Figure 4A). With the exception of a decrease in dynorphin A levels in the olfactory tubercle, there were no other differences in peptide levels observed (Figures $4 \mathrm{~B}$ and data not shown for MEAP).

Because both the Acb and frontal cortex are involved in responses to stressful stimuli, and as nociceptin may be an endogenous anxiolytic-like agent, it was necessary to determine if stress altered nociceptin levels in these brain regions (Jenck et al. 1997; Jenck et al. 2000; Horger and Roth 1996). Rats were repeatedly exposed to mild footshock stress in operant chambers, and footshock was unpredictably reapplied after several weeks of no footshock. This protocol was designed to eliminate any conditioning factors that might be paired with the footshock stress. Nociceptin levels were significantly decreased in the Acb after reexposure to footshock $(p<.05)$. Nociceptin levels demonstrated a trend toward an increase in the frontal cortex $(p=.089$ by Student's $t$-test). Footshock stress also increased nociceptin levels $(p<.001)$ and dynorphin A levels $(p<.05)$ in the olfactory tubercle (Figures 5A and 5B) and had no effect on MEAP levels in any of the brain regions examined (data not shown). 


\section{Nociceptin/Orphanin FQ}

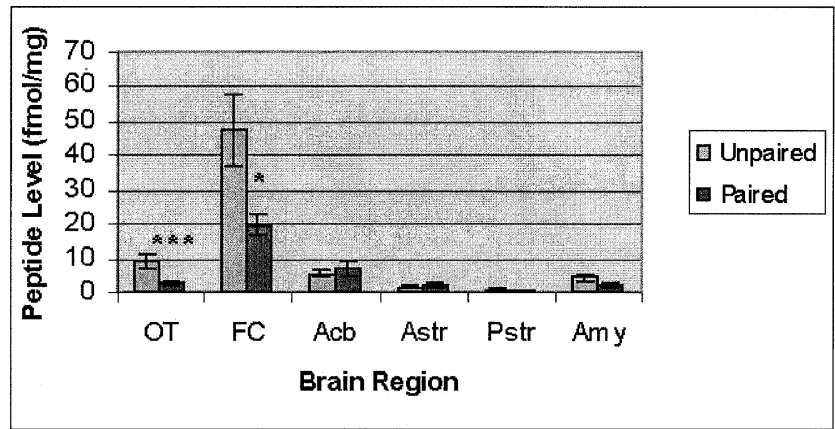

Figure 3. Effect of conditioned opioid withdrawal on nociceptin/orphanin FQ peptide levels in several brain regions. Results are expressed as fmol peptide per milligram protein. Brain regions: OT, olfactory tubercle; FC, frontal cortex; Acb, nucleus accumbens; Astr, anterior striatum; Pstr, posterior striatum; Amy, amygdala. ${ }^{* *} p<.01,{ }^{*} p<.05$ differences between paired and unpaired rats.

\section{DISCUSSION}

Nociceptin peptide levels decreased in the frontal cortex after conditioned opioid withdrawal. Potential roles of the medial prefrontal cortex (mPFC) in drug addiction have been proposed (Tzschentke 2001). Strong synaptic connections with the hippocampus give evidence for a role of the mPFC in learning, memory, and conditioning (Doyere et al. 1993; Hernadi et al. 2000). The $\mathrm{mPFC}$ has also been implicated in relapse to drug seeking (Weiss et al. 2001). Conditioned withdrawal-induced changes in neuropeptide levels in the mPFC could therefore have important implications in drug reward-related behaviors.
Because the frontal cortex is involved in stress and nociceptin has been implicated as an endogenous anxiolytic, we sought to determine whether the change in nociceptin peptide levels might be a response to a stressful component of conditioned withdrawal (Horger and Roth 1996; Jenck et al. 1997). Repeated footshock stress in a stimulus pattern similar to our conditioned withdrawal protocol did not, however, induce changes in nociceptin in the frontal cortex. This result leads to the conclusion that the decrease in nociceptin in the frontal cortex with conditioned opioid withdrawal is independent of any possible stressful component of conditioned withdrawal.

Unconditioned opioid withdrawal increases nociceptin levels in the frontal cortex and decreases nociceptin levels in the Acb. It has been postulated that the mPFC, a component of the frontal cortex, negatively modulates dopamine function in the Acb (Tassin et al. 1978; Mitchell and Gratton, 1992). Both the mPFC and the Acb receive dopamine input from the ventral tegmental area, and lesions of the $\mathrm{MPFC}$ modulate dopamine release in the Acb. Nociceptin may modulate dopamine release into regions postsynaptic to dopamine input and, through this mechanism, may play a role in the interaction between these brain regions (McGregor et al. 1996; King and Finlay, 1997; Konya et al. 1998). Through these interactions, nociceptin may be hypothesized to play a role in the negative reward state associated with unconditioned opioid withdrawal as reflected in operant suppression, ICSS threshold elevation, conditioned place aversion, and locomotor activity suppression (Schulteis et al. 1994).

Modulation of opioid peptide levels during conditioned withdrawal also could be caused by physiological effects similar to those produced by unconditioned withdrawal. Unconditioned withdrawal, however, had

\section{Nociceptin/Orphanin FQ}

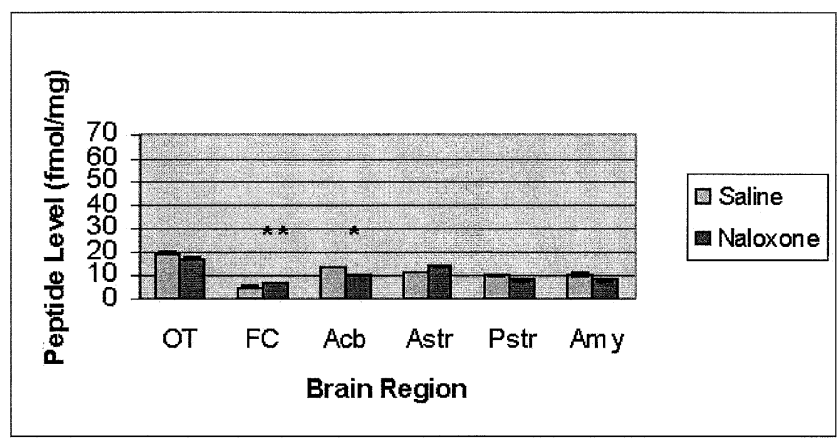

Dynorphin A

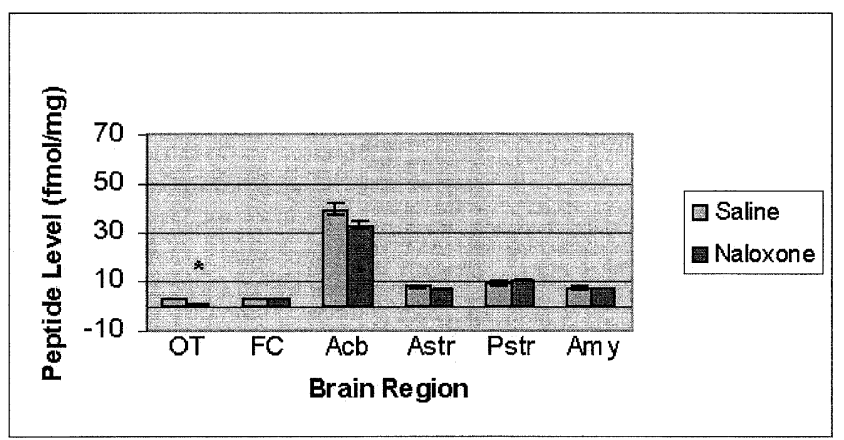

Figure 4. Effect of unconditioned opioid withdrawal on opioid peptide levels in several brain regions. Results are expressed as fmol peptide per milligram protein. Brain regions: OT, olfactory tubercle; FC, frontal cortex; Acb, nucleus accumbens; Astr, anterior striatum; Pstr, posterior striatum; Amy, amygdala. (Left panel) Effect of unconditioned withdrawal on nociceptin/ orphanin FQ levels. (Right panel) Effect of unconditioned withdrawal on dynorphin A levels. ${ }^{* *} p<.01,{ }^{*} p<.05$ differences between naloxone and saline-injected rats. 


\section{Nociceptin/Orphanin FQ}

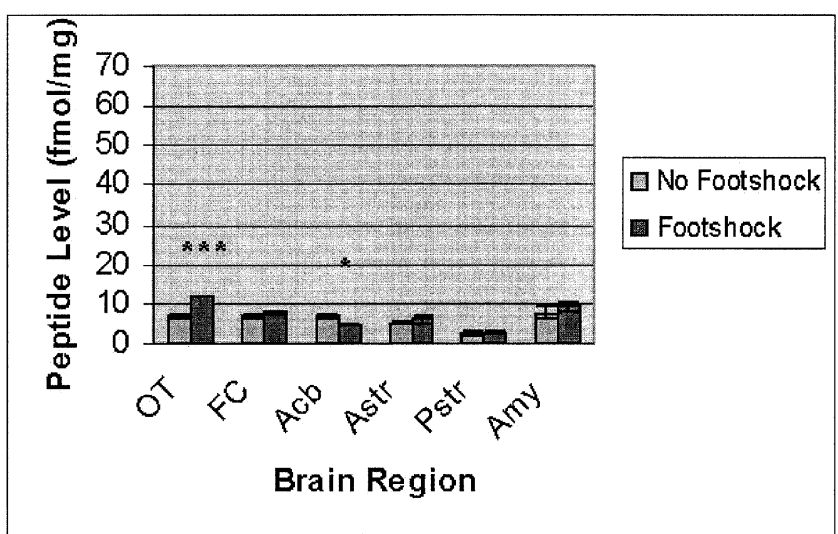

Dynorphin A

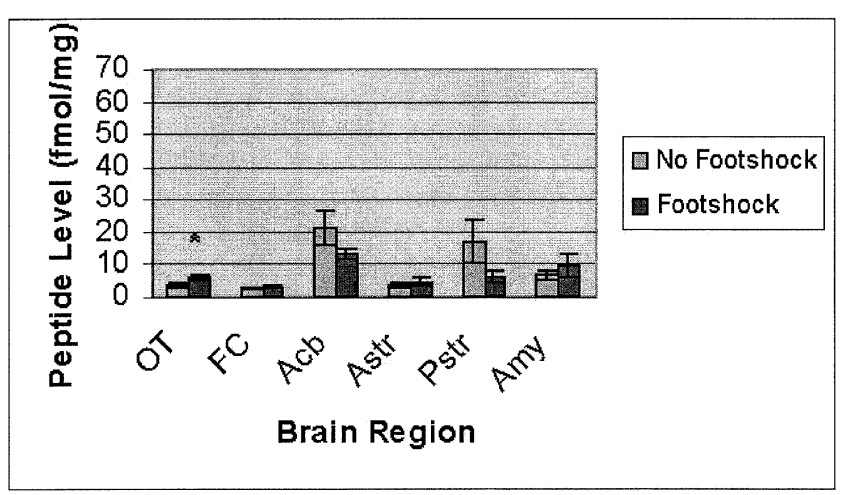

Figure 5. Effect of mild footshock stress on opioid peptide levels in several brain regions. Results are expressed as fmol peptide per milligram protein. Brain regions: OT, olfactory tubercle; FC, frontal cortex; Acb, nucleus accumbens; Astr, anterior striatum; Pstr, posterior striatum; Amy, amygdala. (Left panel) Effect of footshock stress on nociceptin/orphanin FQ levels. (Right panel) Effect of footshock stress on dynorphin A levels. ${ }^{* *} p<.001,{ }^{*} p<.05$ differences between footshock and no footshock.

an opposite effect on nociceptin peptide levels in the frontal cortex (compare Figures 3 and 4A). Opposite effects of conditioned and unconditioned stimuli on neurochemical markers suggest that any similar behavioral effects that may be produced by these two stimuli would occur through distinct mechanisms.

No peptide level changes were observed in our striatal (minus Acb) dissections, a region not directly involved in the rewarding aspects of drug addiction-related behaviors. Also, no peptide-level changes were observed in our amygdala dissections, though the basolateral nucleus of the amygdala recently was shown to have a role in conditioned withdrawal in the same rat model used in this study (Schulteis et al. 2000). Our dissections included, however, the entire amygdala, so effects in amygdaloid subregions may have been diluted and therefore undetectable.

It should be noted that absolute levels of nociceptin peptide were several times higher in the frontal cortex of conditioned withdrawal rats compared with the unconditioned withdrawal and footshock stress rats. This difference could be caused by either the chronic food restriction or the chronic morphine administration required for the conditioned withdrawal study. Opioid peptide levels are altered in food-restricted rats (Berman et.al. 1994), but besides nociceptin, the other peptide levels were consistent across experimental groups in the present study.

It could be argued that the specific decrease in nociceptin that occurred during conditioned withdrawal is caused by the baseline difference (e.g., higher nociceptin levels in the frontal cortex of control animals). Arguments against the baseline being a factor can be made with two observations in the nociceptin data across the three experiments. First, though absolute nociceptin levels were higher in the frontal cortex of the conditioned withdrawal study compared with the unconditioned withdrawal study (compare Figures 3 and 4A), alterations in peptide levels were still detected between saline and naloxone rats (unconditioned withdrawal study). Second, though absolute nociceptin levels in the olfactory tubercle were half as high in the conditioned withdrawal study compared with the unconditioned study, modulation in levels can still be detected (compare Figures 3 and 4A). Thus, higher absolute amounts of nociceptin in the frontal cortex of rats in the conditioned withdrawal study likely does not preferentially permit detection of a decrease in this study.

Finally, in the present experimental design, conditioning occurred only to the tone and smell and not the context of the experimental conditions. When the 10minute pre-injection baseline values were examined in the paired group during the conditioning phase, an increase in responding occurred over the conditioning sessions (Table 1); a decrease would have indicated conditioning to the context. This increase was most likely caused by the recovery in responding that progressively occurs the first several days after morphine pellet implantations (unpublished observations).

Stress and conditioned cues induce relapse in experimental models of drug addiction and are important contributors to relapse in human drug addicts (Goldberg et al. 1969; Shaham et al. 2000). Unconditioned opioid withdrawal has not been shown reliably to induce relapse in animal models, but it does play a role in motivating drug intake in animals that have experience with taking heroin to relieve withdrawal (Hutcheson et al. 2001). Stress, conditioned withdrawal, and uncondi- 
tioned withdrawal were used in this study to examine opioid peptides in several brain regions involved in drug addiction and relapse (Self 1998), and interesting patterns in opioid regulation were revealed. First, a decrease in nociceptin in the frontal cortex with conditioned withdrawal may represent a neurochemical effect distinct to conditioned withdrawal; the same was not observed with unconditioned withdrawal or stress. Second, nociceptin was the peptide regulated in the majority of the significant effects (six of eight), suggesting important roles for this peptide in stimuli that may trigger drug seeking. Third, half of the peptide-level changes observed involved the olfactory tubercle indicating the need for further studies of the role this brain region may play in conditioning, unconditioned withdrawal, and stress. Overall, these results suggest an important role for nociceptin in conditioned opioid withdrawal. Normalization of nociceptin function may alter the behavioral response to cues paired with drug withdrawal, and it should be pursued as a possible means to prevent drug relapse.

\section{ACKNOWLEDGMENTS}

The authors wish to thank Gery Schulteis for helpful discussions and Mike Arends for editorial assistance. This study was supported by National Institute on Drug Abuse research grant (DA04043 to GFK). LT was supported by the Swedish Medical Research Council (Grant 3166). This is publication 14355-NP from The Scripps Research Institute.

\section{REFERENCES}

Baldwin HA, Koob GF (1993): Rapid induction of conditioned opiate withdrawal in the rat. Neuropsychopharmacology 8:15-21

Bergström L, Christensson I, Folkesson R, Stenström B, Terenius L (1983): An ion exchange chromatography and radioimmunoassay procedure for measuring opioid peptides and substance P. Life Sci 33:1613-1619

Berman Y, Devi L, Carr KD (1994): Effects of chronic food restriction on prodynorphin-derived peptides in rat brain regions. Brain Res 664:49-53

Cappendijk SL, Hurd YL, Nylander I, van Ree JM, Terenius L (1999): A heroin-, but not a cocaine-expecting, selfadministration state preferentially alters endogenous brain peptides. Eur J Pharmacol 365:175-182

Christensson-Nylander I, Nyberg F, Ragnarsson U, Terenius L (1985): A general procedure for analysis of proenkephalin B derived opioid peptides. Regul Pept 11:65-76

Ciccocioppo R, Angeletti S, Panocka I, Massi M (2000): Nociceptin/orphanin FQ and drugs of abuse. Peptides 21: 1071-1080

Doyere V, Burette F, Negro CR, Laroche S (1993): Long-term potentiation of hippocampal afferents and efferents to prefrontal cortex: implications for associative learning. Neuropsychol 31:1031-1053

Goldberg SR, Woods JH, Schuster CR (1969): Morphine: conditioned increases in self-administration in rhesus monkeys. Science 166:1306-1307

Hernadi I, Karadi Z, Vigh J, Petyko Z, Egyed R, Berta B, Lenard L (2000): Alterations of conditioned taste aversion after microiontophoretically applied neurotoxins in the medial prefrontal cortex of the rat. Brain Res Bull 53:751-758

Horger BA, Roth RH (1996): The role of mesoprefrontal dopamine neurons in stress. Crit Rev Neurobiol 10:395-418

Hutcheson DM, Everitt BJ, Robbins TW, Dickinson A (2001): The role of withdrawal in heroin addiction: enhances reward or promotes avoidance? Nat Neurosci 4:943-947

Jenck F, Moreau JL, Martin JR, Kilpatrick GJ, Reinscheid RK, Monsma FJ Jr, Nothacker HP, Civelli O (1997): Orphanin FQ acts as an anxiolytic to attenuate behavioral responses to stress. Proc Natl Acad Sci USA 94:14854-14858

Jenck F, Wichmann J, Dautzenberg FM, Moreau JL, Ouagazzal AM, Martin JR, Lundstrom K, Cesura AM, Poli SM, Roever S, Kolczewski S, Adam G, Kilpatrick G (2000): A synthetic agonist at the orphanin FQ/nociceptin receptor ORL1: anxiolytic profile in the rat. Proc Natl Acad Sci USA 97:4938-4943

King D, Finlay JM (1997): Loss of dopamine terminals in the medial prefrontal cortex increased the ratio of DOPAC to DA in tissue of the nucleus accumbens shell: role of stress. Brain Res 767:192-200

Konya H, Masuda H, Itoh K, Nagai K, Kakishita E, Matsuoka A (1998): Modification of dopamine release by nociceptin in conscious rat striatum. Brain Res 788:341-344

Lindholm S, Ploj K, Franck J, Nylander I (2000): Repeated ethanol administration induces short- and long-term changes in enkephalin and dynorphin tissue concentrations in rat brain. Alcohol 22:165-171

Mansour A, Fox CA, Akil H, Watson SJ (1995): Opioidreceptor mRNA expression in the rat CNS: anatomical and functional implications. Trends Neurosci 18:22-29

McGregor A, Baker G, Roberts DC (1996): Effect of 6-hydroxydopamine lesions of the medial prefrontal cortex on intravenous cocaine self-administration under a progressive ratio schedule of reinforcement. Pharmacol Biochem Behav 53:5-9

Mitchell JB, Gratton A (1992): Partial dopamine depletion of the prefrontal cortex leads to enhanced mesolimbic dopamine release elicited by repeated exposure to naturally reinforcing stimuli. J Neurosci 12:3609-3618

O'Brien CP (1996): Drug addiction and drug abuse. In Gilman AG, Hardman JG, Limbird LE, Molinoff PB, Ruddon RW (eds), Goodman and Gilman's The Pharmacological Basis of Therapeutics, 9th ed. New York, McGraw-Hill, pp 557-577

O'Brien CP, Childress AR, Ehrman R, Robbins SJ (1998): Conditioning factors in drug abuse: can they explain compulsion? J Psychopharmacol 12:15-22

O'Brien CP, Testa T, O'Brien TJ, Brady JP, Wells B (1977): Conditioned narcotic withdrawal in humans. Science 195:1000-1002

Reisine T, Pasternak G (1996): Opioid analgesics and antago- 
nists. In Hardman JG, Limbird LE, Molinoff PB, Ruddon RW, Gilman AG (eds), The Pharmacological Basis of Therapeutics, 9th ed. New York, McGraw-Hill, pp 521-555

Schulteis G, Ahmed SH, Morse AC, Koob GF, Everitt BJ (2000): Conditioning and opiate withdrawal. Nature 405:1013-1014

Schulteis G, Heyser CJ, Koob GF (1997): Opiate withdrawal signs precipitated by naloxone following a single exposure to morphine: potentiation with a second morphine exposure. Psychopharmacology (Berl) 129:56-65

Schulteis G, Markou A, Gold LH, Stinus L, Koob GF (1994): Relative sensitivity to naloxone of multiple indices of opiate withdrawal: a quantitative dose-response analysis. J Pharmacol Exp Ther 271:1391-1398

Self DW (1998): Neural substrates of drug craving and relapse in drug addiction. Ann Med 30:379-389

Shaham Y, Erb S, Stewart J (2000): Stress-induced relapse to heroin and cocaine seeking in rats: a review. Brain Res Brain Res Rev 33:13-33
Shaham Y, Stewart J (1996): Effects of opioid and dopamine receptor antagonists on relapse induced by stress and re-exposure to heroin in rats. Psychopharmacology (Berl) 125:385-391

Tassin JP, Stinus L, Simon H, Blanc G, Thiery AM, Le Moal M, Cardo B, Glowinski J (1978): Relationship between the locomotor hyperactivity induced by A10 lesions and the destruction of the fronto-cortical dopaminergic innervation in the rat. Brain Res 141:267-281

Tzschentke TM (2000): The medial prefrontal cortex as a part of the brain reward system. Amino Acids 19:211-219

Weiss F, Ciccocioppo R, Parsons LH, Katner S, Liu X, Zorrilla EP, Valdez GR, Ben-Shahar O, Angeletti S, Richter RR (2001): Compulsive drug-seeking behavior and relapse. Neuroadaptation, stress, and conditioning factors. Ann NY Acad Sci 937:1-26

Wikler A (1973): Dynamics of drug dependence: implications of a conditioning theory for research and treatment. Arch Gen Psychiatry 28:611-616 